\title{
EXPERIMENTAL TESTING OF THE PROTON EXCHANGE MEMBRANE (PEM) HYDROGEN FUEL CELL PERFORMANCE WITH NANO-GRAPHENE OXIDE
}

\section{Dr. Hazem Tawfik P.E., State University of New York, College of Technology at Farmingdale}

Prof. Tawfik obtained his Ph.D. in Mechanical Engineering, from University of Waterloo, Ontario, Canada. He has held a number of industrial \& academic positions and affiliations with organizations that included Brookhaven National Laboratory (BNL), Rensselaer Polytechnic Institute (RPI), Stony Brook University (SBU), Massachusetts Institute of Technology (MIT), Atomic Energy of Canada Inc., Ontario Hydro, NASA Kennedy, NASA Marshall Space Flight Centers, and the U.S. Naval Surface Warfare Center at Carderock, Md. Dr. Tawfik is the co-author of more than 60 research papers in the areas of Hydrogen Fuel Cells, Biomass Energy, Thermo- fluids and Two Phase Flow published in prestigious peer reviewed journals and conference symposiums. He holds numerous research awards and owns the rights to four patents in the Polymer Electrolyte Membrane (PEM) fuel cells area. Currently, Dr. Tawfik is a SUNY Distinguished Service Professor and the Director of the Institute for Research and Technology Transfer (IRTT) at Farmingdale State College of the State University of New York.

\section{Yeong Ryu, State University of New York, College of Technology at Farmingdale}

YEONG S. RYU graduated from Columbia University with a Ph.D. and Master of Philosophy in Mechanical Engineering in 1994. He has served as an associate professor of Mechanical Engineering Technology at Farmingdale State College (SUNY) since 2006. In addition, he has conducted various research projects at Xerox Corporation (1994-1995), Hyundai Motor Corporation (1995-1997), and New Jersey Institute of Technology (2001-2003). He has been teaching and conducting research in a broad range of areas of system identification and control of nonlinear mechatronic systems and vibrations in structures requiring precision pointing to eliminate the detrimental effects of such diverse disturbance sources. He has authored or co-authored more than 70 publications. His work currently focuses on the development and implementation of modeling and control of renewable energy systems, characterization of nanomaterials, photovoltaics, and nanoscale integrated systems. He is a member of the American Society of Mechanical Engineers (ASME), American Society for Engineering Education (ASEE) and the Materials Research Society (MRS). 


\title{
EXPERIMENTAL TESTING OF THE PROTON EXCHANGE MEMBRANE (PEM) HYDROGEN FUEL CELL PERFORMANCE WITH NANO-GRAPHENE OXIDE
}

\begin{abstract}
:
Currently researchers are focusing their efforts on producing Nano-size materials to optimum their catalytic functionality and other physical and chemical properties for many engineering and technology applications. Among the advantages of Nano-size materials are their very high surface area to volume ratio and high chemical reaction rate. Nano size carbon-based materials such as Graphene Oxide (GO) is one substance known to have good features including chemical stability, high durability, and relatively good cost effectiveness. GO exhibits high chemical stability over a wide temperature range in both acidic and alkaline conditions, making it the most economically viable candidate as an effective component in the electrodes in electrochemical energy devices such as Proton Exchange Membrane (PEM) fuel cells. There are many available carbon allotropes, but graphene is considered an important asset for energy generation applications with unique characteristics such as good chemical stability and excellent electrical conductivity.
\end{abstract}

Platinum is by far the most effective element currently used in industry as a PEM fuel cell catalyst, and nearly all PEM fuel cells are using platinum particles on porous carbon supports to catalyze both Hydrogen Oxidation Reaction (HOR) on the anodic side and Oxygen Reduction Reaction (ORR) on the cathodic side of a fuel cell. However, due to the platinum high cost, current Pt/C catalysts are not feasible for commercialization. Hence, this project is performed to investigate the effect of nano-graphene oxide on the fuel cell performance when added to the carbon black as the traditional catalyst support in the fuel cell electrodes. Therefore, the following factor was examined:

- The effect of nano-graphene oxide on the ORR activity of platinum electro-catalyst and the overall influence on fuel cell performance, when it is added to the carbon black catalyst support in the cathodic side.

- Percentage effect on the cost of the fuel cell by reducing the amount of platinumbased catalysts as a precious metal.

As a result of adding nano graphene-oxide to the catalyst support in the anodic electrode of a PEM fuel cell, the present experimental work indicating a significant rise in power.

\section{INTRODUCTION:}

A fuel cell is a device that uses hydrogen (or hydrogen-rich fuel) and oxygen from air to create electricity. The PEM fuel cell consists of a proton exchange electrolyte membrane sandwiched between an anode (negative electrode) and a cathode (positive electrode). The membrane sandwiched is technically termed as the Membrane Electrode Assembly (MEA) that consists of nafion membrane, electrodes, catalyst loading, and gas diffusion layer pressed together. Since the 
manufacturing of the MEA is time consuming, in this study, two pieces of a 5-layer MEA was purchased from fuel cell store with customized dimensions.

Hydrogen fuel (H2) is admitted to the anode channels as the first reactant gas, where the HOR takes place in the presence of the catalyst ${ }^{[1]}$, causing the splitting of hydrogen's negatively charged electrons from the positively charged protons. The membrane allows the positively charged protons to pass through to the cathode, but not the negatively charged electrons. The negatively charged electrons must flow around the membrane through an external circuit. This flow of electrons forms an electrical current. Meanwhile, at the cathode, the negatively charged electrons and positively charged hydrogen ions (protons) combine with oxygen under the ORR and the presence of the catalyst to form water $\left(\mathrm{H}_{2} \mathrm{O}\right)$ and heat. The following represents these two chemical reactions:

\section{Anode chemical equation - HOR Cathode chemical equation - ORR $2 \mathrm{H}_{2}+\mathrm{CT} \longrightarrow 4 \mathrm{H}^{+}+4 \mathrm{e}^{-} \quad \mathrm{O}_{2}+4 \mathrm{H}^{+}+4 \mathrm{e}^{-} \longrightarrow 2 \mathrm{H}_{2} \mathrm{O}+$ Heat}

On the other hand, D520 Nafion Dispersion with Alcohol based $1000 \mathrm{EW}$ at 5 wt.\% is known as Chemours (DuPont) Nafion ${ }^{\mathrm{TM}}$ which is a polymer dispersion made from chemically stabilized perfluoro sulfonic acid (PFSA) / polytetrafluoroethylene (PTFE) copolymer in the acid $\left(\mathrm{H}^{+}\right.$) form, and are available in several polymer content and dispersant compositions. Typical uses include fabrication of thin films and coating formulations for fuel cell membranes, catalyst coating, sensors, and a variety of electrochemical applications. In fuel cell applications, Nafion D520 Dispersion (a diluted, liquid form of the same chemical used for a PEM fuel cell membrane) drastically reduces the amount of platinum needed as a catalyst by exposing a larger fraction of the platinum to the hydrogen gas. Also, the Nafion acts as a binding agent to hold the platinum, membrane, and gas diffusion layer together.

Graphene Nano-oxide consists of graphene sheet that is composed of a single layer of carbon atoms linked in hexagonal shapes, as shown in figure (1), with each carbon atom covalently bonded to three other carbon atoms. Due to it covalent bonding, graphene exhibits high tensile strength, great stability, and electrically conductive ${ }^{[2]}$.

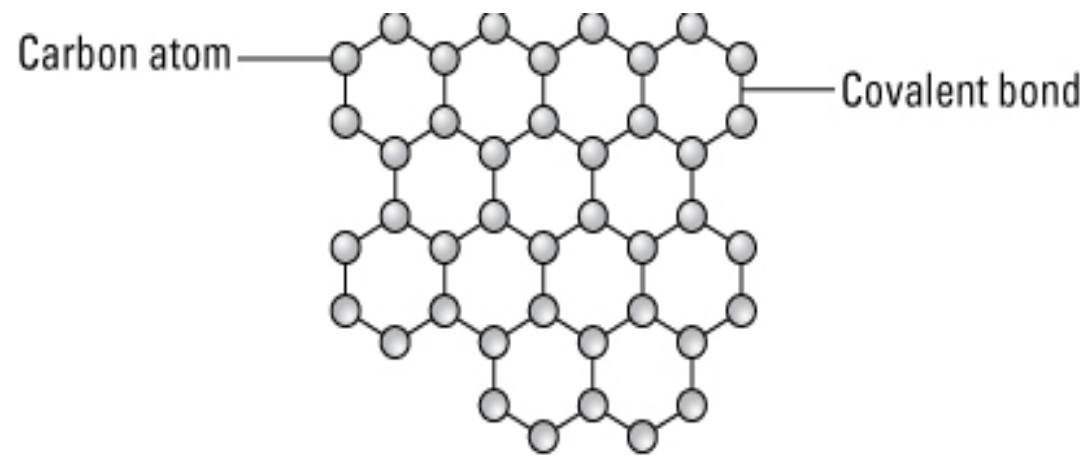

A graphene sheet

Figure (1) A single layer of carbon atoms linked in hexagonal shapes

There are numerous methods to synthesize graphene oxide from a natural graphite. Some of the most common methods are the modified Hummers method, redox method and the chemical vapor 
deposition method. In the present work, a 100mg of graphene Nano oxide was acquired from the graphene supermarket.

\section{Experimental Work:}

In the present work the five layers MEAs were acquired with the following properties as shown in Table (1) below.

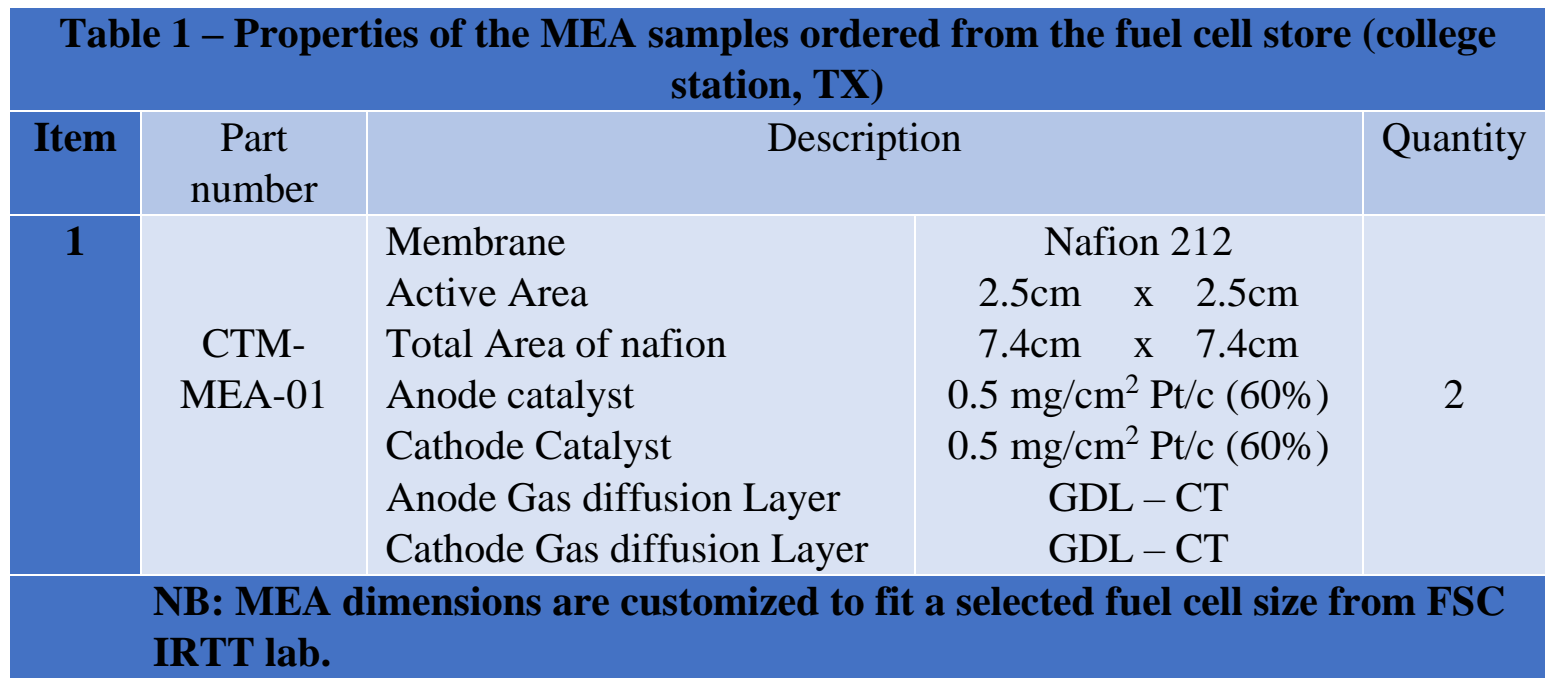

The graphene properties used in the present work are summarized in Table (2) below ${ }^{[3]}$.

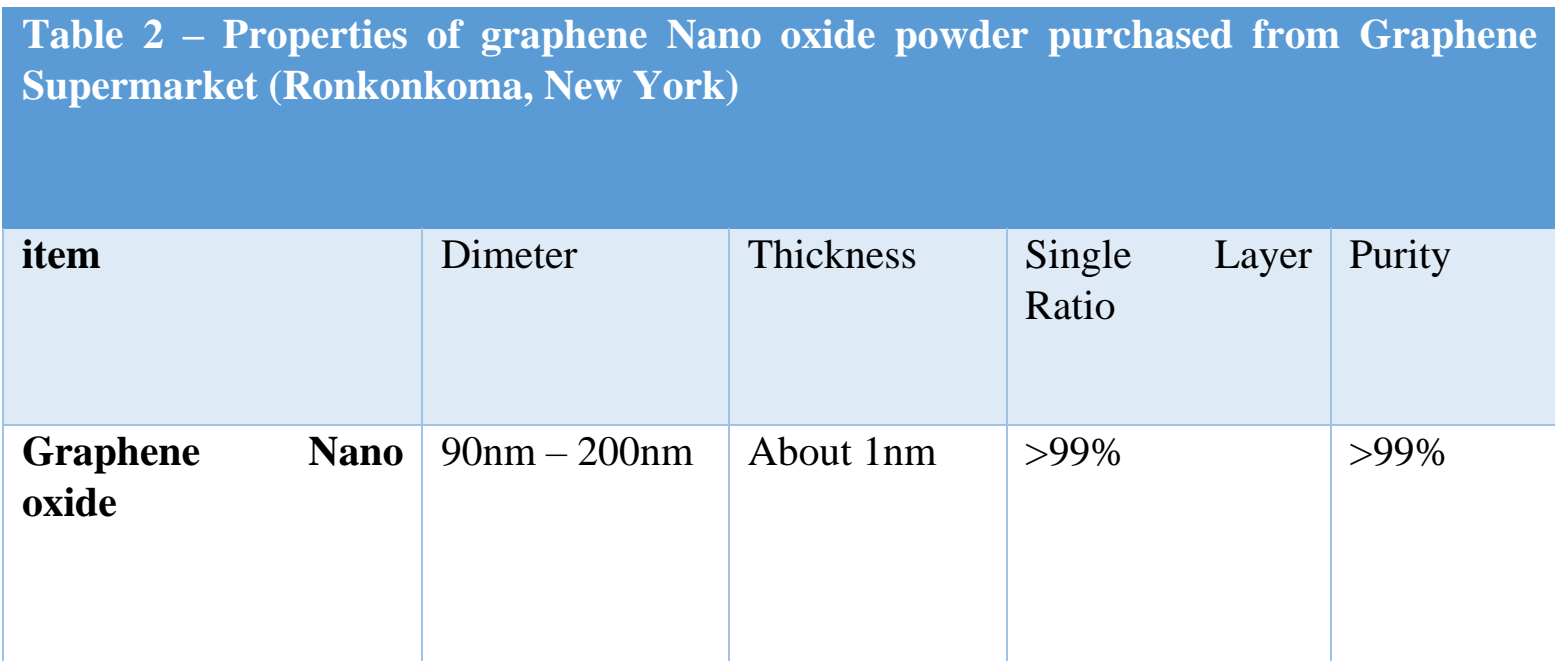

NB: Values provided by the manufacturer 


\section{Experimental preparation of the nano-graphene oxide solution:}

Items needed: 100mg of nano-graphene oxide powder, deionized water, funnel, beaker, and pipette as shown in Figure (2).

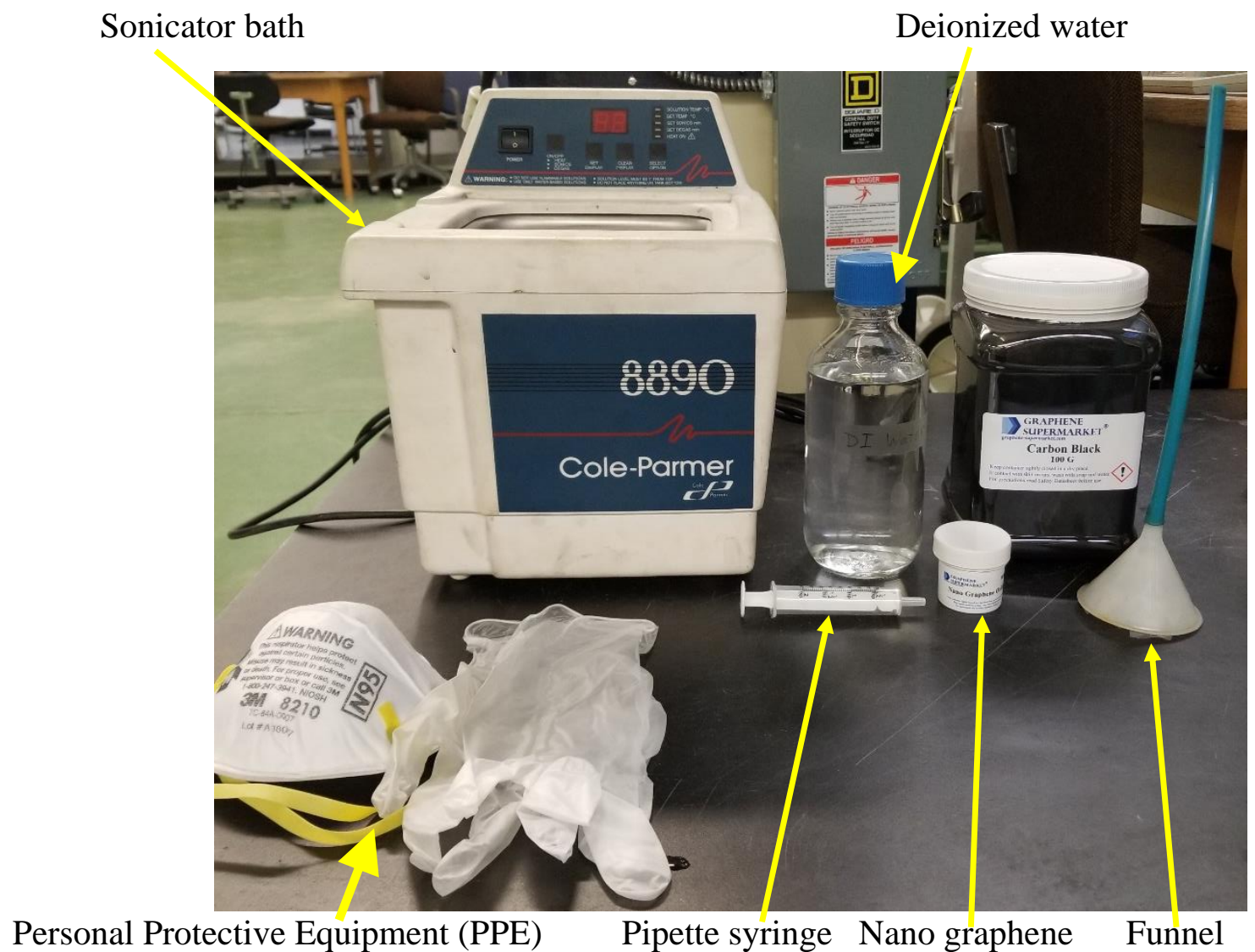

Figure (2) Experimental setup for nano-graphene oxide preparation

1) Experimental Procedure for nano graphene oxide preparation:

a) Personal protection equipment was worn for safety requirement.

b) $40 \mathrm{ml}$ of deionized water was poured into the beaker

c) The container carrying the nano graphene oxide was opened and immediately covered with the funnel in an upside-down position. This is to prevent the Nano particle from escaping into the atmosphere due to its minimal weight

d) $25 \mathrm{ml}$ of DI water was transferred from the beaker into the graphene container using the pipette via a funnel.

e) The solution was then poured into an empty beaker for sonication. the sonicator was set to run for 120 minuites under $23^{\circ} \mathrm{C}$ temperature. See picture for results in Figure (3). 


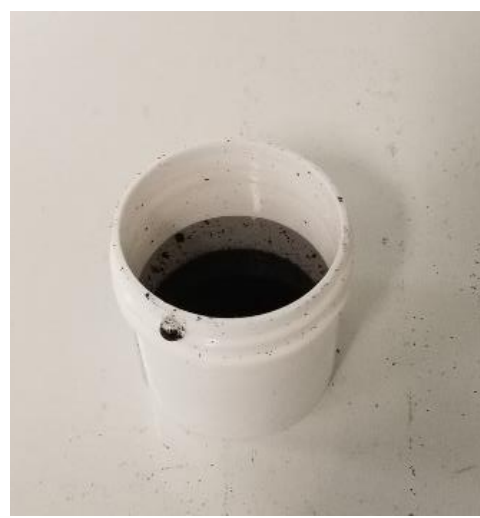

Before sonication

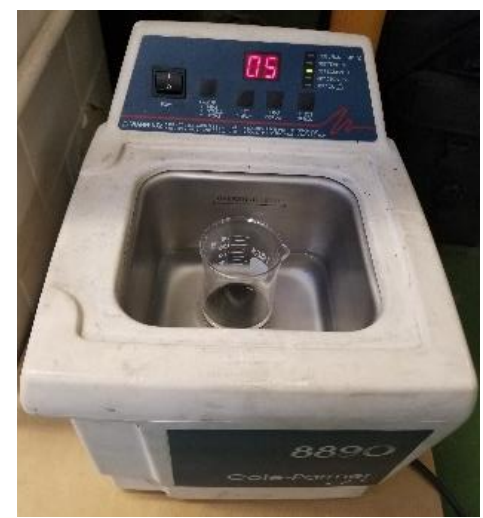

During sonication

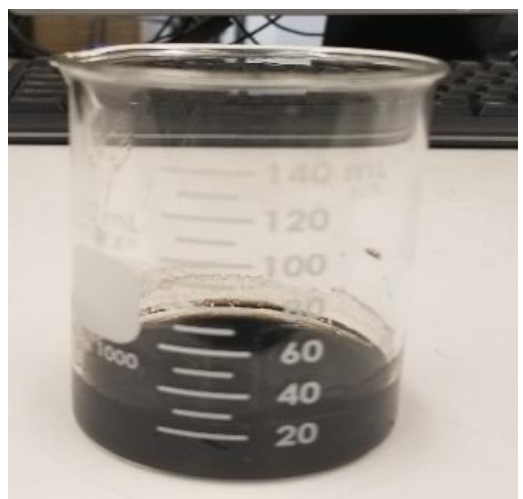

After sonication

Figure (3) Exhibits sonication sequence and procedure

NOTE: THE ENTIRE PROCEDURE WAS PERFORMED UNDER THE HOOD TO LIMIT THE EFFECT OF AIR.

2) One cell fuel cell was fabricated with active area $2.5 \times 2.5 \mathrm{~cm}$ Active area, nano graphene oxide added only to the cathodic electrode where more concentration of platinum catalyst is needed as shown in Figure (4).

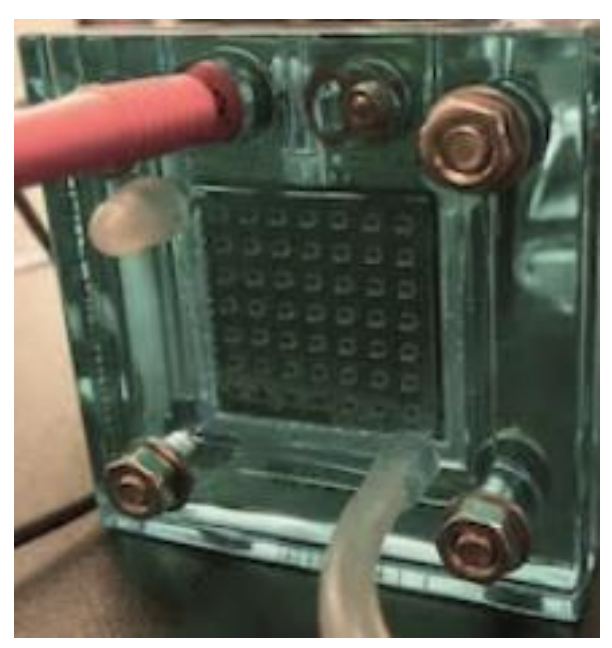

Figure (4) One cell - PEM Fuel Cell

3) A complete testing station was assembled to measure the power output of the PEM fuel cell as shown in Figure (5) with the addition of the nano-graphene oxide to the carbon black as the catalyst support on the cathodic electrode. This setup is shown in Figure (5) and it consists of the following items:

a) Two liters hydrogen tank

b) One PEM $2.5 \mathrm{~cm} \times 2.5 \mathrm{~cm}$ active area used for testing with and without nano-graphene oxide 
c) DC Electronic load tester

d) Hydrogen pressure flow regulators
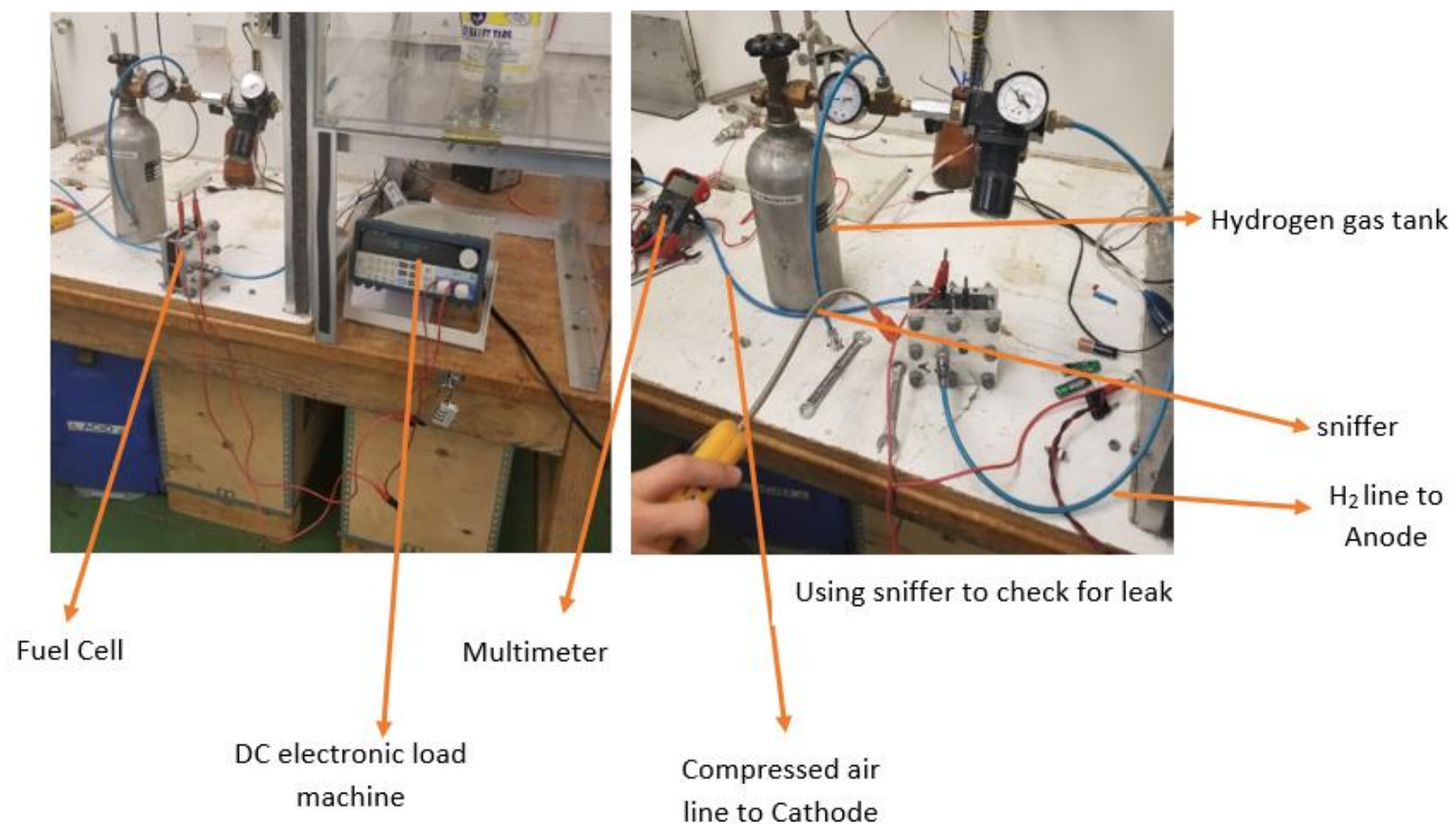

Figure (5) Complete experimental testing station for measuring fuel cell power output and performance evaluation

4) Experimental procedure for evaluating fuel performance:

a) $1.45 \mathrm{psi}$ of hydrogen gas was supplied to the anode side of the fuel cell while supplying 2psi of air/oxygen to the cathode.

b) The test was run for the above set parameters and repeated 4 times for each run for better accuracy.

c) The sniffer was used to detect any leak of hydrogen gas during the process to the surrounding area as an indication for any necessary adjustments need to be made for safety purposes.

d) The DC electronic load machine was used to display the voltage, current and power output of the fuel cell on a computer screen.

e) The multimeter was used to confirm/check the values displayed on the computer and obtained by the electronic load.

f) This test was performed under a hood for additional safety.

5) Procedure for evaluating the Fuel Cell performance with the addition of nano-graphene solution in liquid Nation as shown in the following:

a) $5 \mathrm{ml}$ of the nafion liquid was mixed with $5 \mathrm{ml}$ of the sonicated nano-graphene oxide. 
b) The mixture was shake rigorously until a uniform mixture was obtained.

c) 5 drops of the mixture were deposited on the side designated as the cathodic end of the MEA.

d) The drops on the MEA were allowed to dry before using in the fuel cell assembly for testing setup as described earlier in this paper.

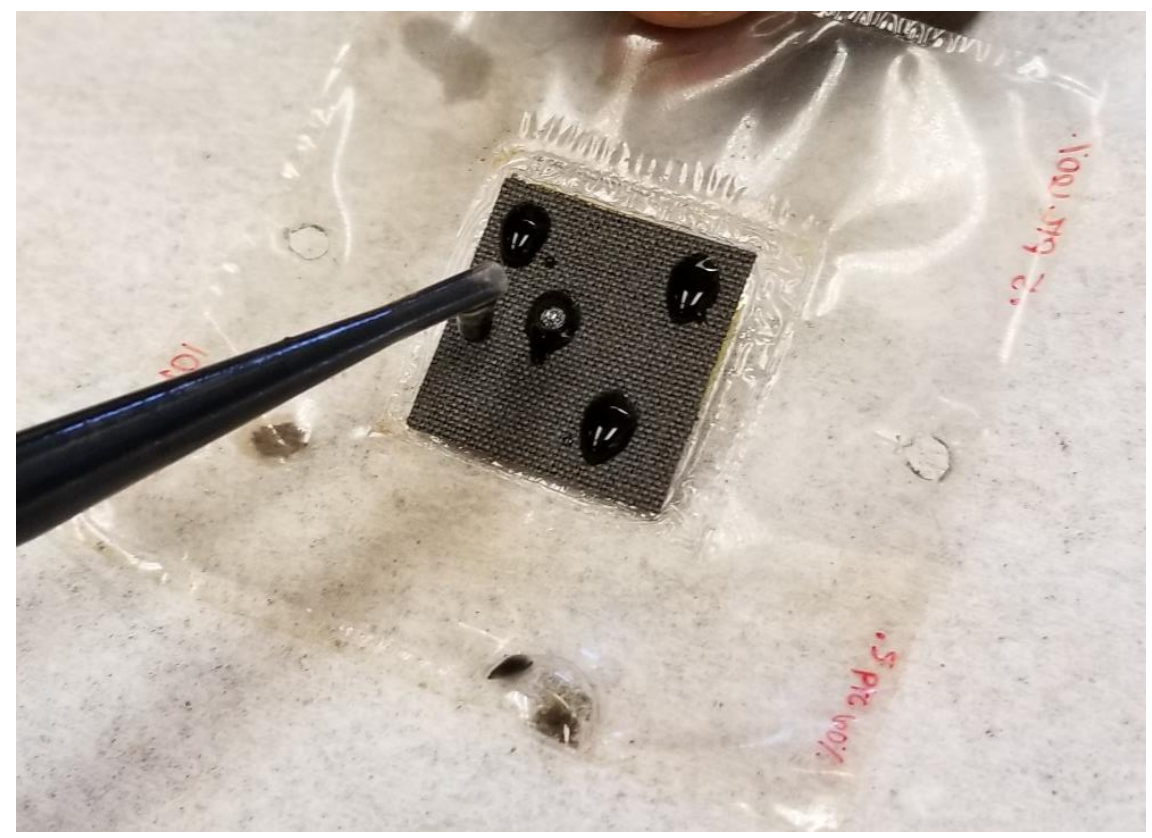

Figure (6) MEA with Graphene solution depositing

6) Results:

From the Figure (7) it is observed that power increases with increasing current. The power curve for the graph with no graphene application increased from $0.006 \mathrm{~W} / \mathrm{in}^{\wedge} 2$ to $0.0035 \mathrm{~W} / \mathrm{in}^{\wedge} 2$ meanwhile the graph with graphene on the cathodic side has increased from $0.008 \mathrm{~W} / \mathrm{in}^{\wedge} 2$ to $0.0052 \mathrm{~W} / \mathrm{in}^{\wedge} 2$ indicating a $67 \%$ increase in power output. This is considered a significant enhancement in the cell performance. 


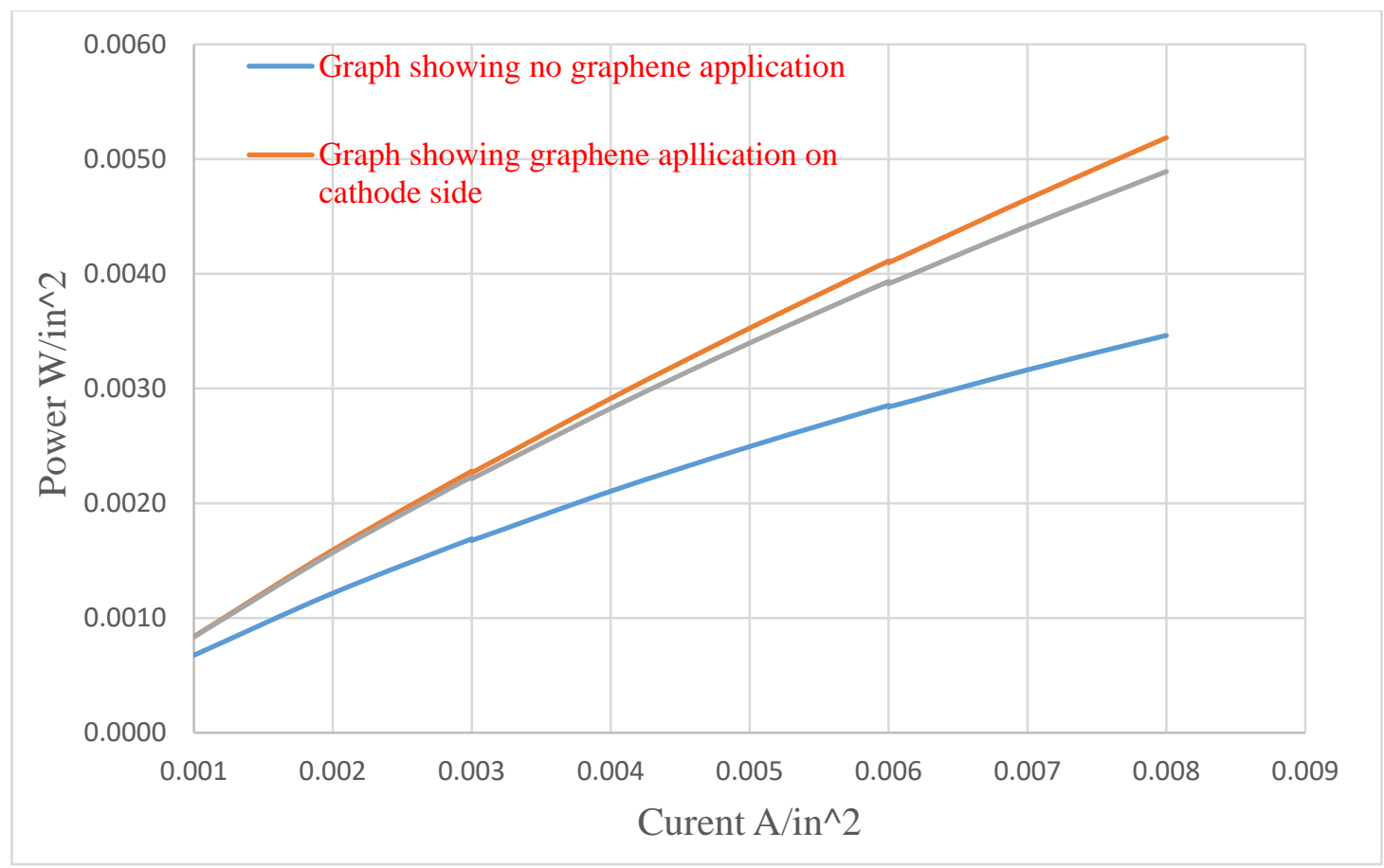

Figure (7) Depicts the Fuel cell performance with and without nano-graphene deposition

\section{Impact in Engineering Technology Education:}

A major objective of this project is to enhance the educational experiences for engineering students while working on a project resembling a realistic work environment similar to that of an industrial setting. The outcome of such learning experiences from this effort will be the design, implementation, statistical analysis, and experimental application in the near future of an interdisciplinary project for engineering students. This future continuation of this research work will involve concepts from electrochemistry, instrumentation, and data acquisition/systems.

Emerging technologies such as those involving alternative sources of energy are expected to play a major role in modern engineering technology curricula because of its positive effect on climate change. The results presented in this paper involve expertise from multidisciplinary teams in our School of Engineering Technology (SET); Major parts of this work were performed as student senior projects in the school of engineering technology at Farmingdale State College supported by the Department of Energy (DOE). It is expected that this lab setup will be used in future undergraduate senior projects for students in the departments of mechanical engineering technology. In addition, interdisciplinary courses in alternative forms of energy, fuel cell, solar, and wind energy systems could be developed in the future as outgrowth of these experimental setups and activities. 


\section{Conclusion:}

In this paper we analyzed the optimal performance of Proton Exchange Membrane Fuel Cells (PEMFCs) which function by the reaction of hydrogen and oxygen from air, in the presence of Platinum as a catalyst, to produce water and energy. Nano-graphene deposition on the Proton Exchange Membrane (PEM) Fuel Cell does show significant effect on the PEM fuel cell performance amounts to $67 \%$.

Therefore, the authors intend to continuously investigate the utilization of graphene oxide in minimizing the amount of platinum, as a precious metal, to reduce the PEM fuel cell overall price and improve its commercialization.

\section{References:}

[1] Marinkas, Arena, et al. "Graphene as catalyst support: The influences of Carbon additives and catalyst preparation methods on the performance of PEM fuel cells." Elsevier, Feb. 2013, pp. 139150.

[2] Marinkas, Hempelmann, et al. "Enhanced Stability Multilayer graphene - supported catalyst for electrolyte membrane fuel cell cathodes." Journal of power sources, July 2015, pp.79-91.

[3] Nano Graphene Oxide Powder, 100 mg. Graphene supermarket, 2018, graphenesupermarket.com. Assessed Oct. 2018. 